\title{
Ciclo de mejora en el aula aplicado a la asignatura Tendencias Literarias en la Cultura Contemporánea: narrativas y micro-narrativas.
}

\section{Improvement Cycle in Classroom applied to the Literary Trends in Contemporary Literature subject: narratives and micro-narratives.}

Miguel ÁNGeL RIVERo GómeZ

ORCID: https://orcid.org/0000-0002-0783-5778

Universidad de Sevilla

Dpto. Literatura Española e Hispanoamericana

mrivero1@us.es

DOI: http://dx.doi.org/10.12795/9788447231003.059

Pp.: 1251-1272 


\section{Contexto del aula y la asignatura}

El presente Ciclo de Mejora en el Aula -CIMA- se ha desarrollado en la asignatura "Tendencias Literarias en la Literatura Contemporánea", del Grado de Comunicación Audiovisual de la Universidad de Sevilla. Su docencia está alineada al Departamento de Literatura Española e Hispanoamericana, y es de las pocas asignaturas del conjunto del Grado en las que se forma al alumnado en el campo de la lengua y la literatura, junto con Lengua Española y Escritura Creativa. El grupo cuenta con 27 alumnos matriculados y la asistencia media durante la aplicación del CIMA ha sido de 19 alumnos.

Se trata de mi primera experiencia en el campo de la innovación docente, tan necesaria para la enseñanza universitaria hacia la que vamos caminando y que requiere salir de modelos pedagógicos anquilosados. Ha sido planificada en una intervención total de 8 horas, de cara al tema de la asignatura titulado "Narrativas Contemporáneas", que he considerado idóneo para el desarrollo de una práctica docente por las posibilidades que brindaba a la hora de acercar al alumnado a prácticas de escritura, de la que lamentablemente están tan desasistidos en los diferentes grados de la Facultad de Comunicación. Precisamente esa carencia, detectada desde las primeras sesiones de la asignatura, ha sido la que ha motivado centrar el CIMA en el campo de la narrativa, buscando la conciliación entre una formación histórica sobre la literatura contemporánea y una dimensión capaz de estimular sus habilidades creativas, expresivas y de escritura.

A través de la elaboración y puesta en práctica del CIMA, he buscado desarrollar procesos de autorreflexión sobre mi propia labor docente, así como una reformulación de la misma a partir del proceso enseñanza-aprendizaje centrada en las preguntas-problema como vía de vertebración de dicho proceso, y en la estrategia trazada por Don Finkel orientada a "dejar que hablen los libros" y a "dejar que hablen los estudiantes" (Finkel, 2008, pp. 47-102). 


\section{Diseño previo del CIMA}

\section{Mapa de contenidos}

Nuestro mapa de contenidos se ha estructurado a partir de dos contenidos estructurantes, cuyo recorrido marca el desarrollo del CIMA y que se corresponden con las preguntas esenciales a abordar en el tema Narrativas Contemporáneas, siendo a su vez su análisis reflexivo el objetivo a alcanzar a lo largo del proceso de enseñanza-aprendizaje. El recorrido se compone también de contenidos conceptuales, equivalentes a la dimensión teórica del tema (la narrativa española del siglo XX y sus diferentes corrientes, autores y obras). En cuanto a los contenidos intelectuales, por un lado, estaría el análisis crítico de la obra de Juan José Millás y, por otro, el debate reflexivo en torno a la crisis de la palabra ante la dominante cultura de la imagen, y las conclusiones a las que dicho debate conduce. A ello hemos de sumar un contenido procedimental, correspondiente a un taller de escritura breve, con el cual el alumnado desarrolla desde la práctica de la escritura creativa buena parte de los supuestos estudiados a nivel teórico. Finalmente, en el recorrido del mapa juegan un papel esencial las "preguntas-problema”, que hacen de hilo de conductor entre los contenidos conceptuales e intelectuales, y los contenidos estructurantes, dotando de solidez y coherencia al conjunto del mapa y al despliegue del proceso de enseñanza-aprendizaje.

Ciclos de Mejora en el Aula (2020). Experiencias de Innovación Docente de la US Esta obra se distribuye con la licencia Creative Commons 


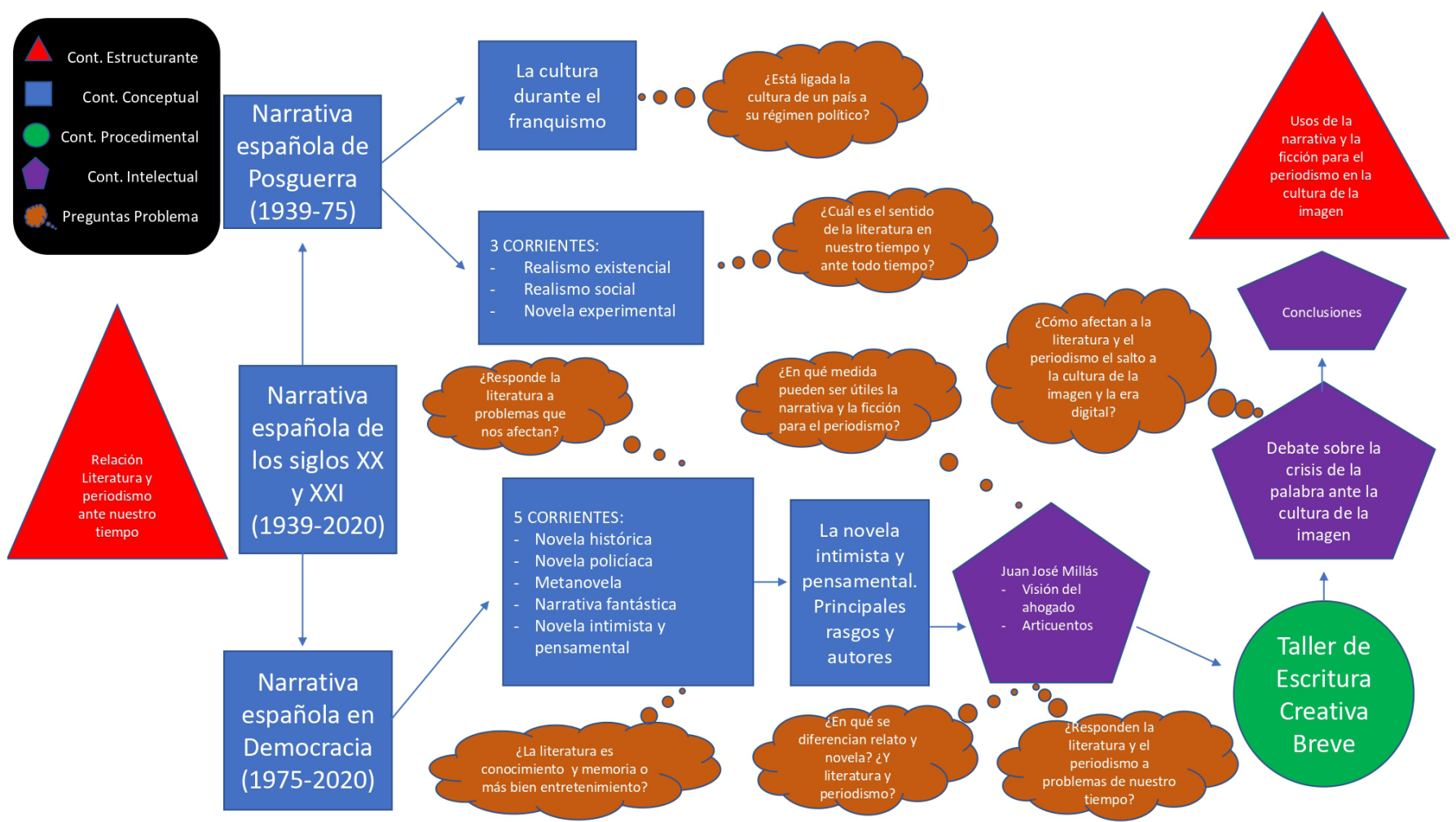

Figura 1. Mapa de contenidos

Ciclos de Mejora en el Aula (2020). Experiencias de Innovación Docente de la US

cc (i) Esta obra se distribuye con la licencia Creative Commons

cc) (i) $\Theta$ Reconocimiento-NoComercial-SinObraDerivada Internacional (CC BY-NC-ND 4.0.) 


\section{Modelo Metodológico}

El modelo metodológico elegido para el desarrollo del CIMA ha procurado huir del "modelo basado en la transmisión" y acercarse a un "modelo basado en la reelaboración de las ideas de los estudiantes" (De Alba y Porlan, 2017). En esa dirección, tras iniciar cada sesión con un sumario de la clase anterior, una sintesis de los contenidos a trabajar y un planteamiento de las preguntas-problema que la articularán, el resto del tiempo se dedica a la exploración de las ideas del alumnado sobre cuestiones vinculadas con las preguntas-problema a indagar y en relación con sus intereses, primero, mediante debates y, luego, mediante actividades de contraste. De este modo, podremos anular la verticalidad tradicional en el proceso de enseñanza y poner en práctica un modelo metodológico más horizontal, donde el alumnado, sus ideas, su reflexión en proceso y sus modelos mentales son protagonistas. Además, el ejercicio de dicho modelo permite dotar a la docencia de una estructura sólida y flexible a un tiempo, y cohesiona el proceso de enseñanza-aprendizaje.
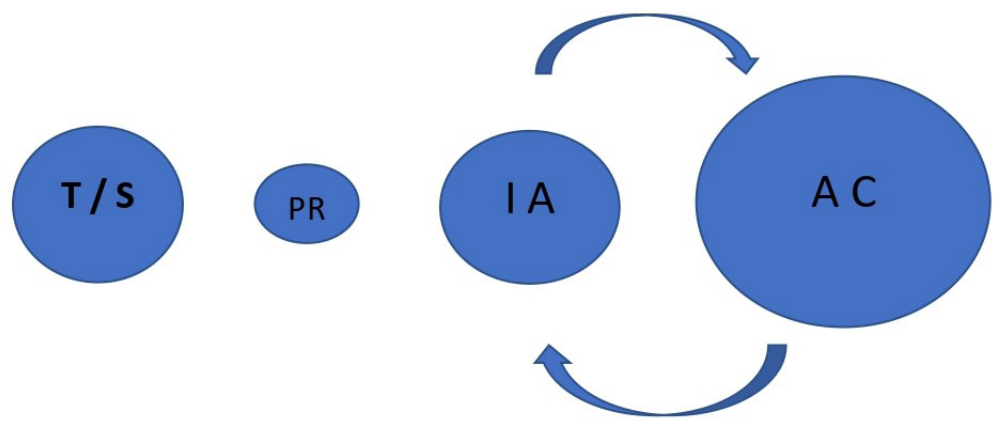

Figura 2. Modelo metodológico

T - Test de diagnóstico inicial

$S$ - Sintesis clase anterior y sumario clase actual

PR - Preguntas-problema
IA - Ideas de los/as alumnos/as AC - Actividades de contraste

Ciclos de Mejora en el Aula (2020). Experiencias de Innovación Docente de la US Esta obra se distribuye con la licencia Creative Commons 


\section{Secuencia de Actividades}

La secuencia de actividades está determinada por el modelo metodológico, de manera que tras las actividades iniciales (sumario de la sesión y planteamiento de preguntas-problema), se realiza un doble recorrido desde las ideas del alumnado sobre cuestiones concretas, vinculadas a las preguntas problema de la sesión e indagadas desde un debate colectivo, hasta las actividades de contraste con las que se abordarán las ideas del alumnado y se trabajarán los contenidos conceptuales e intelectuales. Aportamos a modo de ejemplo la Tabla de la secuencia de actividades de las dos primeras sesiones, al ser la primera y parte de la segunda equivalentes a la que utilizaremos como modelo en la escalera de aprendizaje, a fin de poder apreciar así la evolución de los modelos mentales de los estudiantes.

Tabla 1. Secuencia de actividades

\begin{tabular}{|c|c|c|c|}
\hline \multicolumn{4}{|c|}{ Sesión 1. 26.10.2020 Facultad de Comunicación, Aula 3.1 } \\
\hline $\mathrm{ACT}$ & DESCRIPCIÓN & RECURSOS & TEMP \\
\hline $\mathrm{T} / \mathrm{S}$ & $\begin{array}{l}\text { Test de diagnóstico inicial y sumario de los } \\
\text { contenidos de la presente clase. }\end{array}$ & $\begin{array}{l}\text { Test como } \\
\text { Actividad en PEV }\end{array}$ & 15 \\
\hline PR & $\begin{array}{l}\text { Planteamiento de la preguntas-problemas } \\
\text { de esta sesión: ¿Está la cultura ligada a } \\
\text { los cambios políticos y sociales de un } \\
\text { país? ¿Cuál es el sentido de la literatura en } \\
\text { nuestro tiempo y ante todo tiempo? }\end{array}$ & $\begin{array}{l}\text { Microfonía del } \\
\text { aula }\end{array}$ & 5 \\
\hline $\mathrm{IA}$ & $\begin{array}{l}\text { Preguntas al alumnado sobre la dictadura } \\
\text { franquista, sus impresiones sobre cómo } \\
\text { condicionó a la cultura en general, en } \\
\text { concreto, al género narrativo, desde sus } \\
\text { mecanismos de censura y su ideario del } \\
\text { nacional-catolicismo. } \\
\text { Se abrirán las preguntas y se abordarán } \\
\text { primero con debates en grupos de } 4 \text { y luego } \\
\text { con un debate colectivo. }\end{array}$ & $\begin{array}{l}\text { Ordenador, } \\
\text { proyector } \\
\text { y pantalla, } \\
\text { para recursos } \\
\text { textuales y } \\
\text { audiovisuales }\end{array}$ & 15 \\
\hline
\end{tabular}

Ciclos de Mejora en el Aula (2020). Experiencias de Innovación Docente de la US Esta obra se distribuye con la licencia Creative Commons 


\begin{tabular}{|c|c|c|c|}
\hline$A C$ & $\begin{array}{l}\text { Exposición teórica sobre la narrativa } \\
\text { española de posguerra en sus } 3 \text { fases: } \\
\text { Realismo existencial (1942-51), Realismo } \\
\text { social (1954-62) y Novela experimental } \\
\text { (1962-74). Mención de las obras narrativas } \\
\text { de mayor relevancia. Lectura de fragmentos } \\
\text { de estos } 3 \text { tipos de novelas: Nada, de } \\
\text { Carmen Laforet; Réquiem por un campesino } \\
\text { español, de Ramón J. Sender; Reivindicación } \\
\text { del Conde Don Julián, de Juan Goytisolo. } \\
\text { Continuación del debate colectivo, a partir } \\
\text { de los contenidos expuestos y las lecturas } \\
\text { realizadas, y en conexión con las preguntas } \\
\text { planteadas. }\end{array}$ & $\begin{array}{l}\text { Ordenador, } \\
\text { proyector } \\
\text { y pantalla, } \\
\text { para recursos } \\
\text { textuales y } \\
\text { audiovisuales }\end{array}$ & 35 \\
\hline $\mathrm{IA}$ & $\begin{array}{l}\text { Preguntas al alumnado sobre la Transición } \\
\text { democrática en España y los cambios que } \\
\text { supuso el final de la dictadura, a nivel } \\
\text { político-social y en el campo de la cultura. } \\
\text { Las preguntas se abordarán primero con } \\
\text { debates en grupos de } 4 \text { y luego con un } \\
\text { debate colectivo. }\end{array}$ & $\begin{array}{l}\text { Ordenador, } \\
\text { proyector } \\
\text { y pantalla, } \\
\text { para recursos } \\
\text { textuales y } \\
\text { audiovisuales }\end{array}$ & 15 \\
\hline$A C$ & $\begin{array}{l}\text { Exposición teórica sobre los cambios a } \\
\text { nivel político-social que supuso el fin de } \\
\text { la dictadura y la llegada a la Transición } \\
\text { Democrática, en sus avances y en su } \\
\text { dimensión conflictiva (corrupción política, } \\
\text { paro, terrorismo de ETA y grupos de } \\
\text { extrema-derecha, drogas, delincuencia, la } \\
\text { movida, vaciamiento ideológico). Análisis } \\
\text { reflexivo de los cambios en el campo } \\
\text { de la cultura (salto al "Estado cultural", } \\
\text { industrialización de la cultura, mecenazgo } \\
\text { institucional) y de la literatura (editoriales, } \\
\text { premios, revistas). Visionado de varios } \\
\text { fragmentos del documental La Transición } \\
\text { española, de RTVE (1993). Continuación del } \\
\text { debate colectivo, a partir de los contenidos } \\
\text { expuestos y el visionado fragmentario } \\
\text { del documental, y en conexión con las } \\
\text { preguntas planteadas. }\end{array}$ & $\begin{array}{l}\text { Ordenador, } \\
\text { proyector } \\
\text { y pantalla, } \\
\text { para recursos } \\
\text { textuales y } \\
\text { audiovisuales }\end{array}$ & 35 \\
\hline
\end{tabular}

Ciclos de Mejora en el Aula (2020). Experiencias de Innovación Docente de la US Esta obra se distribuye con la licencia Creative Commons 
Sesión 2. 28.10.2020 Facultad de Comunicación, Aula 3.1

\begin{tabular}{|c|c|c|c|}
\hline $\mathrm{ACT}$ & DESCRIPCIÓN & RECURSOS & TEMP \\
\hline S & $\begin{array}{l}\text { Sintesis de los contenidos de la clase } \\
\text { anterior y sumario de los de la presente } \\
\text { clase. }\end{array}$ & $\begin{array}{l}\text { Ordenador, } \\
\text { proyector } \\
\text { y pantalla, } \\
\text { para recursos } \\
\text { textuales y } \\
\text { audiovisuales }\end{array}$ & 15 \\
\hline PR & $\begin{array}{l}\text { Planteamiento de las preguntas-problema } \\
\text { de esta sesión: ¿Responde la literatura } \\
\text { a problemáticas que nos afectan? ¿La } \\
\text { narrativa es conocimiento y memoria o más } \\
\text { bien distracción y entretenimiento? }\end{array}$ & $\begin{array}{l}\text { Microfonía del } \\
\text { aula }\end{array}$ & 5 \\
\hline IA & $\begin{array}{l}\text { Preguntas al alumnado sobre cómo pudo } \\
\text { afectar a la literatura y en concreto a la } \\
\text { narrativa, el salto a la Transición y a un } \\
\text { régimen democrático en España. } \\
\text { Se abrirán las preguntas y se abordarán } \\
\text { primero con debates en grupos de } 4 \text { y luego } \\
\text { con un debate colectivo. }\end{array}$ & $\begin{array}{l}\text { Ordenador, } \\
\text { proyector } \\
\text { y pantalla, } \\
\text { para recursos } \\
\text { textuales y } \\
\text { audiovisuales }\end{array}$ & 15 \\
\hline$A C$ & $\begin{array}{l}\text { Exposición teórica sobre la narrativa } \\
\text { española desde la Transición, atendiendo } \\
\text { a } 5 \text { corrientes centrales (novela histórica, } \\
\text { novela policiaca, metanovela, narrativa } \\
\text { fantástica, novela intimista y pensamental) } \\
\text { y a sus autores de mayor relevancia. Lectura } \\
\text { de fragmentos de estos } 5 \text { tipos de novelas: } \\
\text { Un beso de amigo, de Juan Madrid; Soldados } \\
\text { de Salamina, de Javier Cercas; La fuente de } \\
\text { la edad, de Luis Mateo Díez; Makbara, de } \\
\text { Juan Goytisolo; y Obabakoak de Bernardo } \\
\text { Atxaga. } \\
\text { Continuación del debate colectivo, a partir } \\
\text { de los contenidos expuestos y las lecturas } \\
\text { realizadas, y en conexión con las preguntas } \\
\text { planteadas. }\end{array}$ & $\begin{array}{l}\text { Ordenador, } \\
\text { proyector } \\
\text { y pantalla, } \\
\text { para recursos } \\
\text { textuales y } \\
\text { audiovisuales }\end{array}$ & 35 \\
\hline IA & $\begin{array}{l}\text { Preguntas al alumnado a propósito de la } \\
\text { distinción de las funciones de la narrativa, } \\
\text { por un lado, en cuanto conocimiento y } \\
\text { memoria, y por otro lado, como distracción } \\
\text { y entretenimiento. Se abrirán las preguntas } \\
\text { y se abordarán primero con debates en } \\
\text { grupos de } 4 \text { y luego con un debate colectivo. }\end{array}$ & $\begin{array}{l}\text { Ordenador, } \\
\text { proyector } \\
\text { y pantalla, } \\
\text { para recursos } \\
\text { textuales y } \\
\text { audiovisuales }\end{array}$ & 15 \\
\hline
\end{tabular}

Ciclos de Mejora en el Aula (2020). Experiencias de Innovación Docente de la US Esta obra se distribuye con la licencia Creative Commons 


\begin{tabular}{|l|l|l|l|}
\hline AC & Exposición teórica de la corriente de la & Ordenador, & \multirow{2}{*}{ novela intimista y pensamental, atendiendo } \\
nroyector & 35 \\
a sus autores fundamentales. Lectura de & y pantalla, \\
3 fragmentos de: Relatos sobre la falta & para recursos & \\
de sustancia, de Álvaro Pombo; La lluvia & textuales y \\
amarilla, de Julio Llamazares; y Todas las & audiovisuales \\
almas, de Javier Marías. Continuación del \\
debate colectivo, a partir de las lecturas \\
realizadas y en conexión con las preguntas \\
planteadas: si la narrativa es conocimiento \\
y memoria o más bien distracción y \\
entretenimiento.
\end{tabular}

\section{Test de diagnóstico inicial-final}

El uso de un test de diagnóstico al inicio y al final del CIMA ha constituido una herramienta fundamental en su desarrollo. Primero, con objeto de aproximarnos a los modelos mentales de los estudiantes y, en función de los mismos, trazar el proceso de enseñanza-aprendizaje. Segundo, para poder detectar y evaluar al final del CIMA los avances realizados por parte del alumnado, usando para ello las escaleras de aprendizaje. Hay que tener en cuenta que resulta "necesario que los estudiantes den sentido a la nueva información desde sus propios modelos mentales $y$, de forma consciente y activa, los modifiquen y reestructuren." (Rivero y Porlán, 2017, p. 76). A esto hemos de sumar la estrecha vinculación entre las cuestiones del test de diagnóstico y el mapa de contenidos, especialmente, los contenidos estructurantes y las preguntas-problema, lo cual dota al proceso de enseñanza-aprendizaje de una mejor organización, consistencia y coherencia.

El test de diagnóstico inicial se desarrolló en el aula, participando 18 estudiantes de 27 matriculados, y el Test de diagnóstico final, debido a las restricciones a la docencia presencial, de manera on line, participando 21 estudiantes.

1) Considera si la narrativa ejerce una función social en nuestro tiempo, respondiendo a problemas que nos afectan, y justifica tu respuesta brevemente. 
2) Señala si el sentido o función de la narrativa en los siglos XX-XXI es relativo a memoria y conocimiento, o más bien a distracción y entretenimiento.

3) Reflexiona en qué medida la literatura y la ficción pueden ser herramientas útiles para el ejercicio del periodismo.

4) Considera si el salto hacia el mundo digital y la cultura de la imagen, donde la palabra pierde cada vez más protagonismo, tendrá consecuencias para la literatura y el periodismo.

\section{Aplicación del CIMA}

\section{Resumen de las sesiones}

De cara a la primera sesión de aplicación del CIMA, la actitud del alumnado conjuga cierta extrañeza y curiosidad a un tiempo. Sin embargo, la explicación del mapa contenidos, del modelo metodológico con el que trabajaremos y de la secuencia de actividades activa su interés, generando una inquietud positiva y un apto clima de trabajo. El comenzar con el Test de diagnóstico inicial refuerza esa inquietud, dada la importancia que les aseguro tendrá para el desarrollo del CIMA y en su proceso de enseñanza-aprendizaje, haciéndoles ver que las preguntas del Test vertebrarán la docencia de este tema en la asignatura. Acto seguido, pasamos a las preguntas-problema en torno a las cuales se estructura esta primera sesión: ¿Está la cultura ligada a los cambios políticos y sociales de un país? ¿Cuál es el sentido de la literatura en nuestro tiempo y ante todo tiempo? La parte relativa a las Ideas de los alumnos se desarrolla desde preguntas concretas sobre sus conocimientos de la dictadura de Franco y sobre cómo consideran que condicionó a la cultura. Por mi parte, limito mi participación a moderar las intervenciones e ir guiando las preguntas. En 
sus intervenciones, apelan a cuestiones como el peso de la iglesia católica y del militarismo dentro del régimen, lo que me da pie a hablarles de los mecanismos de censura que el franquismo desplegó frente a editoriales, medios de prensa, teatros, cines... La actividad de contrate sobre las preguntas planteadas nos lleva a ver cómo algunos de los novelistas más significativos de la literatura española de posguerra siguieron escribiendo y publicando en aquel clima de censura. Analizamos a continuación las tres corrientes fundamentales de la narrativa española de posguerra y leemos fragmentos de algunas obras, procurando también ejercer de guía e intervenir lo mínimo, para que identifiquen las claves de lectura y las relaciones con las preguntas-problema planteadas. Les sorprende que la novela de Ramón J. Sender no pasase los filtros de la censura y fuese publicada en México, de modo que su curiosidad sí parece haberse activado con esta cuestión. De hecho, a propósito del fragmento leído de Nada, de Carmen Laforet, aluden al miedo interior que debió ir acumulando la gente tras la experiencia de la guerra, señalando que ahí radicaba otro mecanismo de censura del régimen aún mayor. El resto de intervenciones aluden a cómo la moral católica afin al régimen fue otro mecanismo de censura interno, alcanzando así estados emocionales intensos en el aula, con una integración casi completa de la clase en el debate y en las cuestiones abordadas, lo cual me sorprendió gratamente. Tras cerrar este debate, volvemos a las Ideas de los alumnos para ir enlazando una serie de preguntas sobre la Transición democrática en España y sobre los cambios que supuso el final de la dictadura, tanto a nivel político-social como en el campo de la cultura. Sin embargo, sus intervenciones son escasas, debido acaso que saben poco sobre la Transición en la historia de España, lo cual determina mi Actividad de contraste, basada en el visionado de varios fragmentos seleccionados del documental La Transición española, de RTVE (1993), y en su posterior debate.

Ciclos de Mejora en el Aula (2020). Experiencias de Innovación Docente de la US Esta obra se distribuye con la licencia Creative Commons 
La segunda sesión arranca con una síntesis de la sesión anterior y con el planteamiento de las preguntas-problema que abordaremos: ¿Responde la literatura a problemáticas que nos afectan? ¿La narrativa es conocimiento y memoria o más bien distracción y entretenimiento? De cara a las Ideas de los alumnos les interrogo sobre cómo el salto a un régimen democrático en España pudo afectar a la literatura. La participación del alumnado no resulta fácil en este terreno, ni con la organización de debates por grupos, ni con el debate colectivo. Confío en la Actividad de contraste para activar su interés y su participación, de manera que procuro ser muy sintético exponiendo las 5 corrientes centrales (novela policiaca; novela histórica; novela intimista y pensamental; metanovela y antinovela, y narrativa fantástica). Dedicamos así la mayor parte del tiempo a leer y comentar con ellos fragmentos breves de 5 obras, cada una perteneciente a una corriente: Un beso de amigo, de Juan Madrid; Soldados de Salamina, de Javier Cercas; La fuente de la edad, de Luis Mateo Díez; Makbara, de Juan Goytisolo; y Obabakoak de Bernardo Atxaga. Mis propósitos son que observen desde los textos mismos, más allá de la clásico exposición teórica, los diferentes estilos y líneas temáticas de cada corriente, y activar su interés por estas narrativas desconocidas para ellos. Les llama la atención la crudeza del lenguaje con el que describe Juan Madrid la ciudad e identifican situaciones con nuestro tiempo, lo cual les abre los ojos a cómo la literatura responde a problemas que nos afectan. También les motiva la novela de Javier Cercas, Soldados de Salamina, que vinculan con lo que vimos en la clase anterior sobre el tema del franquismo, haciendo que el debate colectivo tome cuerpo entre diversos alumnos, atendiendo a la memoria histórica, la actualidad de la censura desde las redes sociales... Me interesa que vean cómo la novela tiene que ver con el conocimiento y la memoria, una de las preguntas-problema planteadas para esta sesión, y el fragmento de Cercas nos ha llevado en esa dirección. En el resto de los fragmentos de las otras

Ciclos de Mejora en el Aula (2020). Experiencias de Innovación Docente de la US Esta obra se distribuye con la licencia Creative Commons 
novelas, su interés es algo menor, si bien incido en la importancia del uso de recursos literarios, la experimentación narrativa, el territorio de la ficción... Es el momento de volver a las ideas de los alumnos para preguntarles sobre las funciones de la narrativa, por un lado, en cuanto conocimiento y memoria, y por otro lado, como distracción y entretenimiento. De cara a seguir reforzando esta idea, en la Actividad de contraste vamos a leer varios fragmentos del género de la novela intimista y pensamental, y así volvemos a enlazar con el debate de la novela como memoria y conocimiento. Las intervenciones de los alumnos se suceden ante La lluvia amarilla, de Julio Llamazares, sobre todo por el hecho de atender a una problemática de nuestro tiempo, la España vaciada. Parece que aquí sí hemos logrado conectar con sus intereses, pues casi todas las intervenciones van en esa dirección y constatan la evidencia de la literatura tiene que ver con problemas que nos afectan y que además testimonian. Les recuerdo que para la próxima clase deben traer leídas de Juan José Millás, la novela Visión del ahogado -1977- y una selección de sus Articuentos -2011- a su disposición en la Plataforma de Enseñanza Virtual.

La tercera sesión genera una mayor expectativa, pues aquí se iniciará el Taller de Escritura Creativa, una de sus grandes motivaciones en el CIMA, debido a la escasez de prácticas de este tipo de que desarrollan en el Grado. Tras la síntesis el sumario de los contenidos, expongo las preguntas-problema que articularán esta sesión: ¿En qué se diferencian los géneros de la novela y el cuento? ¿En qué se diferencian las funciones y los modos de literatura y periodismo? Luego, abro una ronda de preguntas sobre las lecturas de Juan José Millás programadas para esta sesión. Se inicia así un primer acercamiento al autor a partir de un debate colectivo y con mis preguntas busco que los interrogantes del alumnado se orienten a las diferencias entre los géneros de la novela y el cuento, y de la relación 
entre literatura y periodismo. Para ello, me son especialmente útiles los "articuentos" de Millás, textos de carácter híbrido entre el cuento y el artículo de opinión. A su vez la novela me sirve de contraste en cuanto género clásico narrativo. La actividad de contrate comienza de manera natural, gracias en parte a que ya traían las lecturas realizadas desde casa, y en el debate se incide sobre las angustias y neuróticas conductas de los personajes, en las que ven cómo se reflejan dramas de nuestro tiempo como la soledad, la depresión, la personalidad disgregada, los traumas infantiles... Nuevamente volvemos al tema de la literatura como memoria y conocimiento. Acto seguido, pasamos a la lectura y discusión de tres Articuentos de Millás, y retomamos la discusión sobre las diferencias entre los géneros de la novela y el cuento. Percibo que estos textos les resultan especialmente atractivos, que han tocado sus emociones, por el estilo de escritura tan personal y por la vinculación de sus textos de ficción con las realidades más cotidianas. Este recurso a la ficción, que puede parecer un alejamiento de la realidad, constituye por el contrario un modo de abordar la realidad más allá de los límites que la realidad impone. Esa es la virtualidad que ofrece la literatura de ficción al periodismo. De este modo, hemos logrado abordar dos de las preguntas-problema de la asignatura. Por un lado, vemos que los límites entre literatura y periodismo son más líquidos y versátiles de lo que nos cuentan los cánones sagrados de ambas. Por otro lado, el alumnado ha visto un ejemplo de cómo la literatura y la ficción pueden ser herramientas útiles para el ejercicio del periodismo. Acto seguido, pasamos a la Actividad de contraste, un taller de escritura creativa breve, donde damos lectura a varios ejemplos textos creativos en el género de la microficción que, según sus reacciones, les han encantado, pues se trata de un formato que por su brevedad se aproxima a modos de comunicación habituales a ellos. El formato de la microficción ha alcanzado sus estados emocionales, acertando a percibir las posibilidades de

Ciclos de Mejora en el Aula (2020). Experiencias de Innovación Docente de la US Esta obra se distribuye con la licencia Creative Commons 
comunicación de este género, para todos ellos desconocido. A continuación, detallo la tarea encomendada para la próxima sesión: la escritura de un articuento y de una microficción. De este modo, han de trabajar desde la escritura creativa, tanto en el ámbito puro de la ficción literaria con la microficción, como en la estrecha relación entre literatura y periodismo a través del articuento.

La sesión final del Ciclo de Mejora en el Aula se avecinaba extraña, dadas las restricciones ocasionadas por la Covid-19, que decretaban la docencia on line en las universidades andaluzas. Sin embargo, la asistencia a esta sesión resulta ser la más numerosa. Tras la sintesis y el sumario de contenidos, planteo las preguntas-problema de esta sesión: ¿En qué medida pueden ser útiles la literatura y la ficción para el ejercicio del periodismo? ¿De qué modo afectan a la literatura y al periodismo, fundadas en la palabra, el salto al mundo digital y a la cultura de la imagen? Las ideas de los alumnos en esta sesión son especialmente relevantes, de modo que comienzo interrogándoles sobre su experiencia en el campo de la escritura creativa a través del taller. Coinciden en que no ha sido fácil para ellos, sobre todo a la hora de concebir la historia y empezar a escribir. Iniciamos entonces la actividad de contraste, la lectura compartida de varias prácticas de escritura de articuentos y microficciones por parte del alumnado. Trabajamos en una corrección colectiva, donde su participación activa es esencial. Van leyendo sus textos de creación y es sorprendente el buen nivel de las historias que han creado, e incido en detalles a corregir, como el uso de lugares comunes y metáforas gastadas, o el empleo de un tono de lenguaje elevado y poco natural. Les planteo que piensen, tras esta experiencia, sobre la utilidad que puedan tener la literatura y la ficción para el ejercicio del periodismo. Siguen relatando sus experiencias y dificultades en este taller de escritura, y reconocen que estos recursos pueden serle muy útiles, si bien otros alumnos opinan

Ciclos de Mejora en el Aula (2020). Experiencias de Innovación Docente de la US Esta obra se distribuye con la licencia Creative Commons 
que para la eficacia del periodismo como comunicación no le conviene contagiarse de demasiado de este espíritu literario y ficcional. El debate colectivo cobra así fuerza, de manera que lo oriento preguntándoles cómo piensan que puede afectar a la literatura y al periodismo, fundados en la palabra, el salto al mundo digital y a la cultura de la imagen. Aprovechando que las correcciones han generado un buen clima de discusión, continuamos el debate colectivo. Como actividad de contraste a esta pregunta, realizamos una lectura textos del campo de los Cultural Studies que analizan nuestro tiempo a partir del imperio de la cultura de la imagen y de la depauperación de la palabra en este escenario de la era digital, y se inicia un debate colectivo sobre si el periodismo ha de tener una responsabilidad ante esta crisis de la palabra. A este respecto, las posiciones del alumnado son diversas. Para terminar, les indico que en la Plataforma de Enseñanza Virtual he subido el Test de diagnóstico para que lo completen de nuevo, y realizamos unas conclusiones sobre este tema de Narrativas Contemporáneas, que fueron las siguientes: 1) la literatura y el periodismo responden a cuestiones de nuestro tiempo y que nos afectan; 2) la literatura y el periodismo operan desde diferentes lenguajes y distintas vías de comunicación, pero pueden mezclarse y deberían contagiarse; 3) los géneros literarios y comunicativos deben irse transformando y salir de definiciones estáticas, caminando a la hibridación; 4) la literatura es testimonio de cada tiempo y lugar, sea desde una obra realista, sea desde una obra de ficción; 5) la literatura es testimonio, memoria y conocimiento, antes de que mera diversión; 6) la práctica de la escritura creativa puede ser muy útil en la formación de todo comunicador; 7) ante nuestro tiempo, por el imperio de la cultura de la imagen, el periodismo debe cuidar a la palabra y para ello debe volver a recurrir a la literatura.

Ciclos de Mejora en el Aula (2020). Experiencias de Innovación Docente de la US Esta obra se distribuye con la licencia Creative Commons 


\section{Evaluación del aprendizaje de los estudiantes}

A partir de los resultados del test de diagnóstico inicial, observamos que los estudiantes tenían, en su mayoría, una concepción estrecha o limitada del género narrativo dentro de la literatura, identificándolo con la ficción. Sobre esa base, apenas percibían su vinculación con las realidades sociales que nos rodean. Eran escasos los estudiantes que, desde una concepción amplia de la narrativa, la vinculaban con problemas que tienen que ver con nuestro mundo. En paralelo a este modelo mental, la mayoría de los estudiantes parten de una separación natural entre conocimiento y entretenimiento. Desde ahí, vinculan la narrativa con el ocio y el entretenimiento, y la separan del conocimiento, que sitúan más bien en un ámbito científico o filosófico, a excepción de ciertas novelas. En cuanto a la vinculación entre literatura y periodismo, encontramos en el test de diagnóstico inicial una distribución bastante equitativa entre tres modelos mentales. En el escalón inferior y medio, los estudiantes mantienen una concepción estrecha del periodismo, vinculado a la objetividad, y ven a la literatura desligada de la realidad, por lo que no la consideran un recurso fiable. En el escalón superior, en cambio, señalan las diferencias entre periodismo y literatura vinculándolas a objetividad y subjetividad, respectivamente, pero ven la literatura útil para el periodismo. Por último, a propósito de las consecuencias que tendrá para la literatura y el periodismo el salto a la cultura digital y el mundo de la imagen, los resultados iniciales no fueron negativos. Tan sólo una cuarta parte de la clase aceptaba sin más esa crisis de la palabra y apostaba por una adaptación a la cultura de la imagen. La tesitura de más de la mitad de la clase señalaba que ese salto digital sería positivo para el periodismo, pero negativo para la literatura. En el escalón superior, una mínima representación de la clase alertaba sobre los peligros de la crisis de la palabra y el imperio de una cultura de la imagen, y apostaba por cuidar de la palabra tanto en el periodismo como en la literatura. 
Tras el desarrollo del CIMA, los resultados que arroja el test de diagnóstico final señalan que, si bien aproximadamente la mitad de la clase permanece en una concepción limitada de la narrativa, en cambio ha crecido notablemente el número de estudiantes con una concepción amplia de la narrativa y vinculada a realidades de nuestro tiempo, independientemente del subgénero de que se trate. Por otra parte, respecto al modelo mental que vincula a la narrativa con el ocio y el entretenimiento, apenas he detectado cambios significativos entre los resultados de los test de diagnóstico inicial y final, de modo que probablemente no se han realizado las actividades de contraste adecuadas. En cuanto a la vinculación entre literatura y periodismo, sí ha experimentado el grupo de estudiantes un cambio significativo, ascendiendo más de la mitad de la clase al primer nivel en la escalera de aprendizaje. Menos de una quinta parte de la clase persiste en separar periodismo y literatura, mientras que el resto los ven como lenguajes distintos, pero conciliables. Considero que este cambio, según el cual la mayoría ha pasado a considerar útil la literatura para el periodismo, se debe al éxito de la actividad de contraste, el taller de escritura creativa. Finalmente, en cuanto al salto a la cultura digital y el mundo de la imagen, el conjunto de la clase ha experimentado un importante crecimiento. Algo más de una cuarta parte permanece en una aceptación de la crisis de la palabra y apuesta por integrarse en la imagen. Otra cuarta parte aproximadamente sigue pensando que el salto digital será positivo para el periodismo, pero negativo para la literatura. Sin embargo, crece ostensiblemente el escalón superior, cuando en el test inicial tan sólo había dos estudiantes. Ahora casi la mitad de la clase se sitúa en este nivel, habiendo tomando conciencia sobre los peligros de la crisis de la palabra y el imperio de una cultura de la imagen, no sólo para la literatura, sino para su futuro oficio, el periodismo. Creo que a ello ha contribuido la línea transversal que ha recorrido las actividades de contraste, buscando derribar los puentes entre periodismo y literatura.

Ciclos de Mejora en el Aula (2020). Experiencias de Innovación Docente de la US Esta obra se distribuye con la licencia Creative Commons 
A modo de ejemplo, incorporamos la escalera de aprendizaje relativa a la primera pregunta del Test de diagnóstico: "Considera si la narrativa ejerce una función social en nuestro tiempo, respondiendo a problemas que nos afectan, y justifica tu respuesta brevemente."

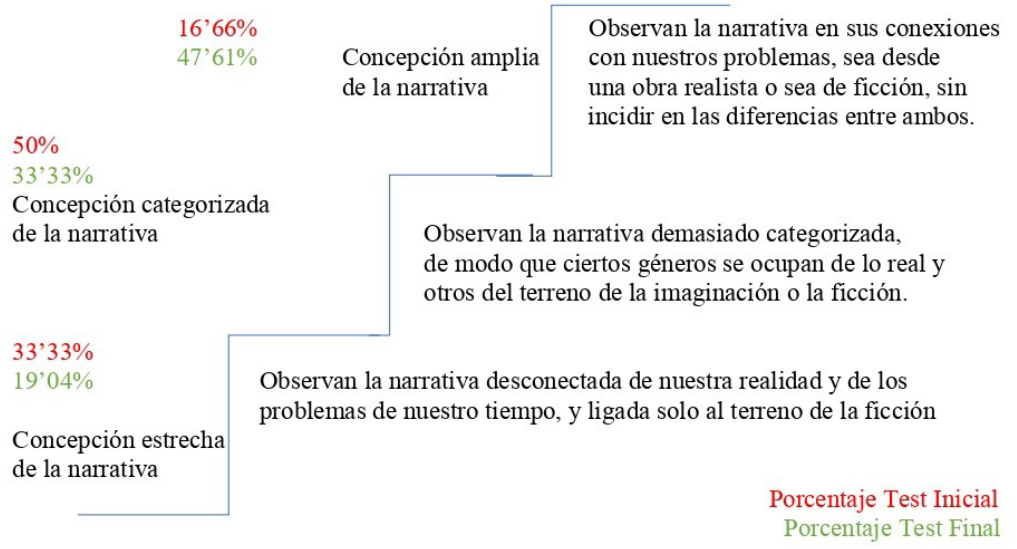

Figura 3. Escalera de Aprendizaje

\section{Evaluación del CIMA}

El resultado sin duda más relevante, de cara a mi práctica docente, de la aplicación del CIMA ha sido la participación de los alumnos. Siempre me he visto con problemas ante ese reto, encontrando grandes dificultades, pese a emplear un modelo basado en leer textos y generar a partir del mismo un debate. La explicación a por qué ha funcionado se debe, creo, a que llevaba bien estructuradas las sesiones, con su secuencia de actividades trazada. Gracias a eso no he caído en cierta dispersión, ni en excesos de exposición teórica, pues de lo contrario no podría haber realizado todas las actividades previstas. Asimismo, al dejar más espacio a los alumnos para su participación, su integración en la dinámica de las clases ha sido creciente. Por otra parte, el hecho además de que las actividades se hayan ido concatenando con las preguntas-problema de la 
asignatura ha generado un hilo conductor que, considero, a los alumnos le ha resultado fácil seguir. También he de destacar el éxito del taller de escritura creativa breve, pues ha generado desde el planteamiento un gran interés por parte de los alumnos, al ver ahí una posibilidad de paliar una grave carencia de su formación como la práctica de la escritura.

No me ha funcionado en muchos momentos la participación de los alumnos, especialmente, en los debates colectivos. Si en sus intervenciones individuales sí he logrado que fuesen más activos, en cambio, no ha sido así en las discusiones colectivas donde mis preguntas a veces se estrellaban en el silencio. Creo que no he sabido guiarlos bien en esos momentos. Quizás debí hacer un seguimiento más estrecho de los grupos en el espacio previo en que cada pequeño grupo de 4 o 5 ha de discutir la cuestión.

De cara al próximo CIMA he de mejorar en diversos aspectos, como por ejemplo buscar vías más efectivas para conectar con los modelos mentales de los alumnos, o ensayar otras maneras de gestionar los debates colectivos. También debo cuidar el ir reduciendo todavía más las exposiciones teóricas y suplirlas por actividades de contraste, que al cabo resultan más efectivas. Otra mejora que debo realizar es relativa al uso de materiales audiovisuales, que generan un mayor interés por parte del alumnado.

Para mi práctica docente habitual, incorporaré diversas estrategias del modelo enseñanza-aprendizaje ensayado en el CIMA. Para empezar, el test de diagnóstico inicial, que me parece una herramienta útil para orientar el proceso de enseñanza-aprendizaje de los alumnos. También, como acabo de mencionar, el reducir mis exposiciones teóricas y hacer uso en su lugar de actividades de contraste. Asimismo, incorporaré a mi docencia la estructuración previa 
de las sesiones, de manera que pueda organizar cada tema según sesiones programadas en torno a las preguntas-problema de la materia que esté impartiendo. Por último, seguiré diseñando estrategias docentes para hacer que la participación de los alumnos sea más activa y protagonista, como he logrado por momentos en estas cuatro sesiones.

Palabras Clave: Tendencias Literarias en la Cultura Contemporánea; Grado de Comunicación Audiovisual; narrativas y micronarrativas; docencia universitaria; experimentación docente universitaria.

Keywords: Literary Trends in Contemporary Literature; Audiovisual Communication Degree; narrative and micro-narratives; University teaching; University teaching experimentation.

Ciclos de Mejora en el Aula (2020). Experiencias de Innovación Docente de la US Esta obra se distribuye con la licencia Creative Commons 


\section{Bibliografía}

Bain, K. (2007). Lo que hacen los mejores profesores universitarios. Valencia: Universitat de Valencia.

De Alba, N. y Porlán R. (2017). La metodología de enseñanza. En R. Porlán Ariza (Coord.), Enseñanza Universitaria. Cómo mejorarla (pp. 37-53). Madrid: Ediciones Morata.

Finkel, D. (2008). Dar clase con la boca cerrada. Valencia: Universitat de Valencia.

Navarro Medina, E. (2018). Un ciclo de mejora docente para la formación de maestros y maestras en Didáctica de las Ciencias Sociales. En Jornadas de Formación e Innovación docente del profesorado (pp. 898-921). Sevilla: Instituto de Ciencias de la Educación - Secretariado de Formación de la Universidad de Sevilla.

Porlán Ariza, R. y Navarro Medina, E. (Coords.) (2019). Ciclos de mejora en el aula. Año 2019. Experiencias de innovación docente de la Universidad de Sevilla. Sevilla: Instituto de Ciencias de la Educación - Secretariado de Formación de la Universidad de Sevilla.

Rivero, A. y Porlán, R. (2017). La evaluación en la enseñanza universitaria. En R. Porlán Ariza (Coord.), Enseñanza Universitaria. Cómo mejorarla (pp. 73-91). Madrid: Ediciones Morata.

Ciclos de Mejora en el Aula (2020). Experiencias de Innovación Docente de la US Esta obra se distribuye con la licencia Creative Commons 